\title{
Effect of adiabatic heating on microstructure evolution in Ti-6Al-4V during high strain rate forging
}

\author{
Mykola Kulakov*, Laurie Da Silva, Aurik Andreu \\ Advanced Forming Research Center, University of Strathclyde, Inchinnan, United Kingdom \\ * Corresponding author mykola.kulakov@strath.ac.uk
}

\begin{abstract}
$\underline{\text { Abstract }}$
The effect of adiabatic heating on microstructure evolution during high strain rate subtransus forging of a Ti-6Al-4V alloy having equiaxed initial microstructure was studied through experiments and modelling. $\varnothing 45 \times 67.5 \mathrm{~mm}$ cylindrical billets with embedded thermocouples were forged at four different $\alpha+\beta$ temperatures on a Schuler $2100 t$ screw press to evaluate the extent of adiabatic heating in different parts of the billet. In the centre of the billet, the highest temperature increase due to adiabatic heating exceeded the $\beta$ transus $\left(\sim 1000^{\circ} \mathrm{C}\right)$ during forging. The microstructure of the forged billets was examined for any changes in $\beta$ phase volume fraction due to adiabatic heating. The forging process was then simulated in Deform 2D/3D software. High strain rate compression testing in the $\alpha+\beta$ and $\beta$ temperature fields was carried out using a Phoenix forge simulator to generate input mechanical properties for the model. The effect of the billet size on the $\alpha-\beta$ phase transformation during forging and post-forge cooling is also discussed.
\end{abstract}

\section{Introduction}

Most of the mechanical energy is dissipated in the form of heat during plastic deformation of metals; only a small fraction is stored in the material. $\alpha-\beta$ titanium alloys have a relatively high flow stress for all $\alpha-\beta$ working temperatures and, therefore, a large amount of heat is generated during hot deformation. The relatively low thermal conductivity of titanium alloys also prevents this heat from being effectively dissipated. High strain rates also limit the time available for the heat dissipation. The combination of these factors results in adiabatic heating during forging. The temperature increase might lead to changes in microstructure of the material and therefore affect the resultant mechanical properties of the forged part. In the present study, the effect of adiabatic heating on the $\alpha$-to- $\beta$ phase transformation in a Ti-6Al-4V alloy during high strain rate forging was examined.

\section{Initial microstructure}

A section of a $\varnothing 335 \mathrm{~mm}$ Ti-6Al-4V bar was provided by TIMET Savoie. The chemical composition conforms to the AMS4928 requirements; the corresponding $\beta$ transus temperature is $1001{ }^{\circ} \mathrm{C}$. Grain size measurements of primary alpha were carried out using MIPAR image analysis software [1]; the average equivalent primary alpha grain diameter was found to be about $14 \mu \mathrm{m}$, Figure $1 . \varnothing 45 \times 67.5 \mathrm{~mm}$ billets for forging trials and $\varnothing 12 \times$ $18 \mathrm{~mm}$ compression samples were machined using this material.
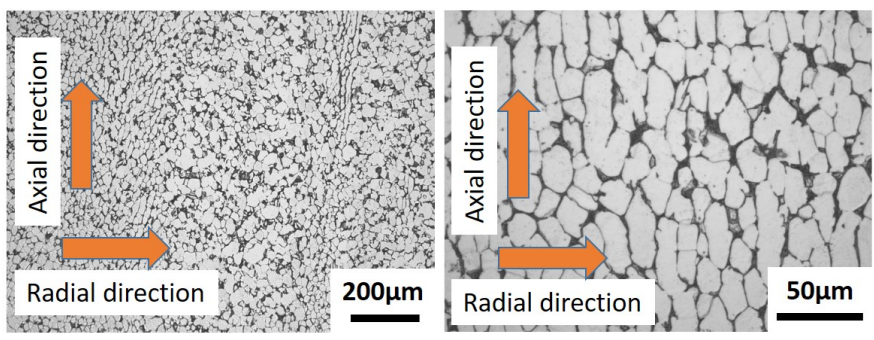

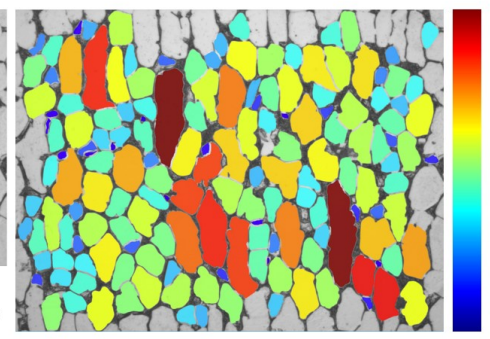

$40 \mu \mathrm{m}$ $30 \mu \mathrm{m}$ $20 \mu \mathrm{m}$ $10 \mu \mathrm{m}$ $0 \mu \mathrm{m}$

Figure 1 Microstructure of as-received Ti-64

\section{Forging trials}

Forging trials were conducted on a $2100 \mathrm{t}$ screw press at $875,900,925$ and $950{ }^{\circ} \mathrm{C}$ using $\varnothing 45 \times 67.5 \mathrm{~mm}$ Ti-6Al-4V billets. Embedded mineral insulated $\varnothing 0.5 \mathrm{~mm} \mathrm{~N}$-type thermocouples were employed to measure the deformation-induced temperature increase. The nominal response time of the thermocouple was $30 \mathrm{~ms}$. The four cylinders were forged with two thermocouples installed in the mid-height plane - at mid-radius and centre. 
During forging, temperature on the surface of a billet was also measured using a LAND R100V dual-wavelength (1.0 and $1.2 \mu \mathrm{m})$ pyrometer. The billets were coated with a glass coating and preheated in a box furnace; after reaching the forging temperature $\pm 5^{\circ} \mathrm{C}$, the billets were kept in the furnace for additional $900 \mathrm{~s}$. Temperature readings were collected using a National Instruments data acquisition board and Signal Express software at a rate of $1000 \mathrm{~Hz}$. The temperature of the dies was about $250{ }^{\circ} \mathrm{C}$ and they were lubricated with a water-based graphite suspension. The billets were upset from 67.5 to $25.6 \mathrm{~mm}$, i.e. $60 \%$ reduction or a true strain of 1 . Following forging, the billets were quenched in water. All four forged billets were sectioned and polished for microstructural examination. Automated image analysis was then carried out using MIPAR image analysis software on backscatter electron micrographs to estimate the volume percentage of transformed $\beta /$ primary $\alpha$ in different locations of the forged billets; the average volume percentage was calculated based on the analysis of 15 micrographs captured at 500x (the total analyzed area was about $0.75 \mathrm{~mm}^{2}$ ).

An example of the temperature measurements for the $950{ }^{\circ} \mathrm{C}$ forging trial is shown in Figure 2. It can be seen that the billet temperature is not uniform before forging; the larger the distance from the centre of the billet, the more the temperature deviates from the nominal forging temperature of $950^{\circ} \mathrm{C}$ due to heat transfer during the removal from the furnace to the press and while resting on the die. The temperature increase due to forging decreases with distance from the centre of the billet presumably due to the lower strain that the material experiences during forging at the periphery compared to the billet centre. In the centre of the billet, where the temperature increase is highest, the temperature stays above the $\beta$ transus for 1.3 s. Following forging, the cooling rate is relatively slow initially, but then it increases significantly after the billet is placed in water for quenching.

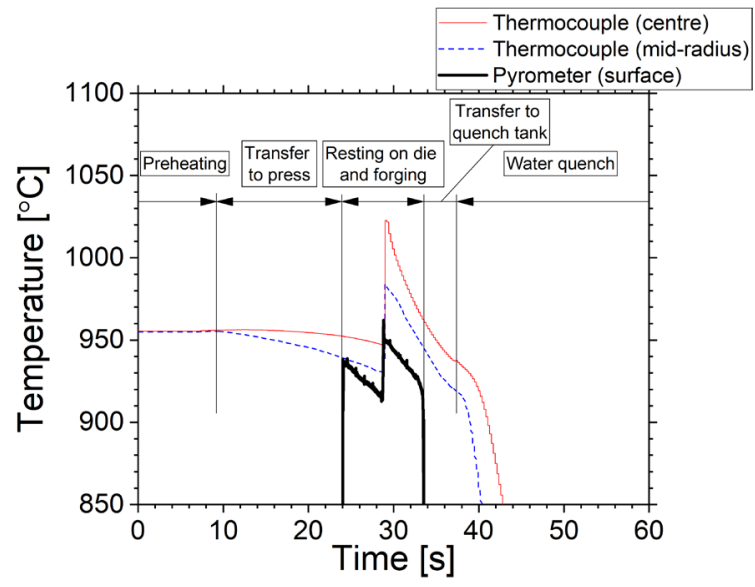

Figure 2 Temperature changes during $950{ }^{\circ} \mathrm{C}$ forging

Backscatter electron micrographs taken in the centre of the four forged billets are shown in Figure 3. Primary alpha is present in all cases; therefore, although the temperature exceeded the $\beta$ transus in the centre during forging, it did not lead to a complete $\alpha-\beta$ transformation. Results of transformed $\beta$ measurements are summarized in Figure 4 . The percentage of transformed $\beta$ is slightly higher than the equilibrium content at 875 and $900{ }^{\circ} \mathrm{C}$ and similar to the equilibrium values at the two highest temperatures. If adiabatic heat triggers the $\alpha-\beta$ phase transformation during forging/post-forging cooling, then a higher percentage of transformed $\beta$ should be observed in the centre of the billet compared to the periphery; for all but the $950{ }^{\circ} \mathrm{C}$ forging temperature, this trend was found. However, the amount of transformed $\beta$ near the edges may have also decreased while handling the billet before the forging due to faster cooling rates near the periphery compared to the centre. 


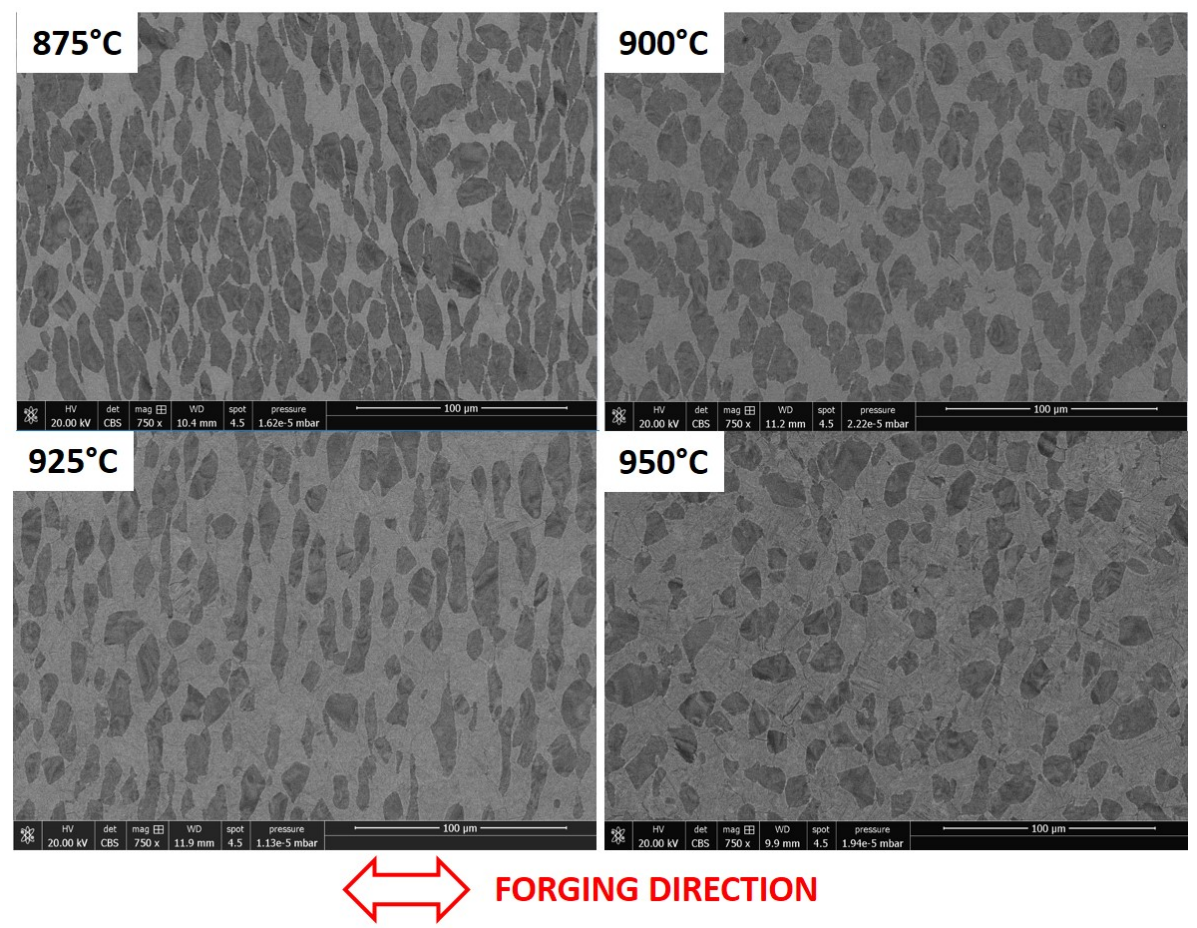

Figure 3 Backscatter electron micrographs taken at the centre of the forged billets

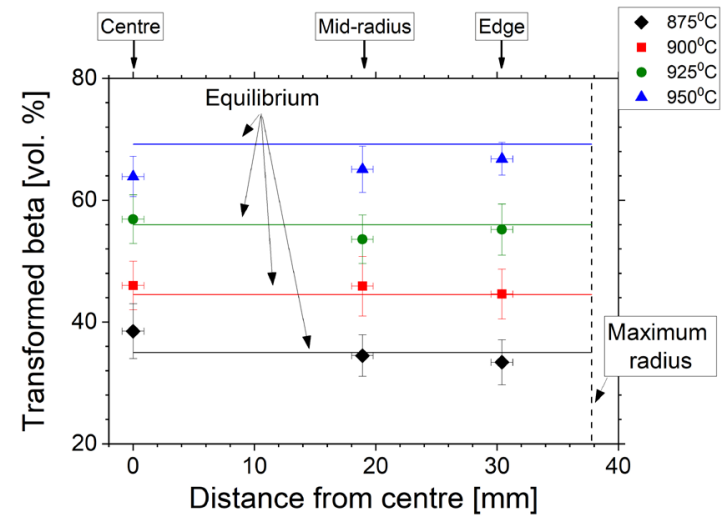

Figure 4 Distribution of transformed $\beta$ in the four billets forged at different subtransus temperatures. Note: Y-error bars indicate $95 \%$ confidence interval, $X$-error bars show where micrographs were taken from, equilibrium $\beta$ phase content was obtained from Pandat database

\section{Modelling}

4.1 Model description

A two-dimensional axisymmetric model of the forging process was developed using Deform 2D/3D software. The $\emptyset 45 \times 67.5 \mathrm{~mm}$ workpiece was modelled as a rigid-plastic material, while the upper and lower dies - as rigid bodies. High strain rate compression tests were carried out using $\varnothing 12$ 
$\times 18 \mathrm{~mm}$ specimens on a Phoenix forge simulator available in the Advanced Forming Research Centre; more information on the forge simulator can be found in [2]. The test matrix comprised of three temperatures $\left(875,950\right.$ and $\left.1025{ }^{\circ} \mathrm{C}\right)$ and three strain rates $\left(5,15\right.$ and $\left.50 \mathrm{~s}^{-1}\right)$. At least two successful tests were conducted for each of the nine combinations of temperature and strain rate. True strain was corrected for the test frame compliance. Furthermore, the stress data was corrected for friction and adiabatic heating. Each pair of flow stress curves for each combination of temperature and strain rate was averaged and smoothed using the moving average filter. The mechanical-to-thermal energy conversion ratio was assumed to be 0.9 for the finite element model of the forging process. The thermal conductivity was obtained from [3]. The heat capacity was calculated using the PanTitanium Pandat database [4] for the chemical composition of the Ti-6Al-4V alloy employed in this study. The billet-air, billet-die (during resting) and billet-die (during forging) heat transfer coefficients were 20,500 and $11000 \mathrm{~W} / \mathrm{m}^{2} / \mathrm{K}$, respectively. Shear friction was assumed between the workpiece and the dies with a constant friction coefficient of 0.3 . Transfer times to/from the press were obtained from videos captured during forging trials.

\subsection{Results and discussion}

Simulated strain distribution, time above the $\beta$ transus maps, and a cross-section of the forged billet are shown in Figure 5 for the $950{ }^{\circ} \mathrm{C}$ forging temperature. The model describes the shape of the billet, i.e., barreling, quite well. The strain distribution map show that a true strain as high as 3 was achieved in the centre of the billet. Temperature in the centre of the billet after forging reaches about $1080{ }^{\circ} \mathrm{C}$, i.e. $80^{\circ} \mathrm{C}$ above the $\beta$ transus. The location where temperature stayed above the $\beta$ transus for the longest time does not correspond to the location of the highest strain; the region between the centre and mid-radius in the mid-height plane experienced temperatures above the $\beta$ transus for the longest time. Both the location of the highest strain and the longest time above the $\beta$ transus are also shifted slightly towards the top of the billet due to the die chilling effect. In the centre of the billet, the experimentally measured peak temperature is lower than that obtained from the model $\left(1030\right.$ vs. $\left.1080{ }^{\circ} \mathrm{C}\right)$ due to a relatively slow response of the thermocouple compared to the forging time $(\sim 100 \mathrm{~ms})$. The steep temperature gradients in the centre of the billet and the difficulty in placing the thermocouple exactly in the centre of the billet also contribute to the observed discrepancy in measured and predicted peak temperatures. However, the experimental time above the $\beta$ transus of $1.3 \mathrm{~s}$ agrees well with the model prediction.

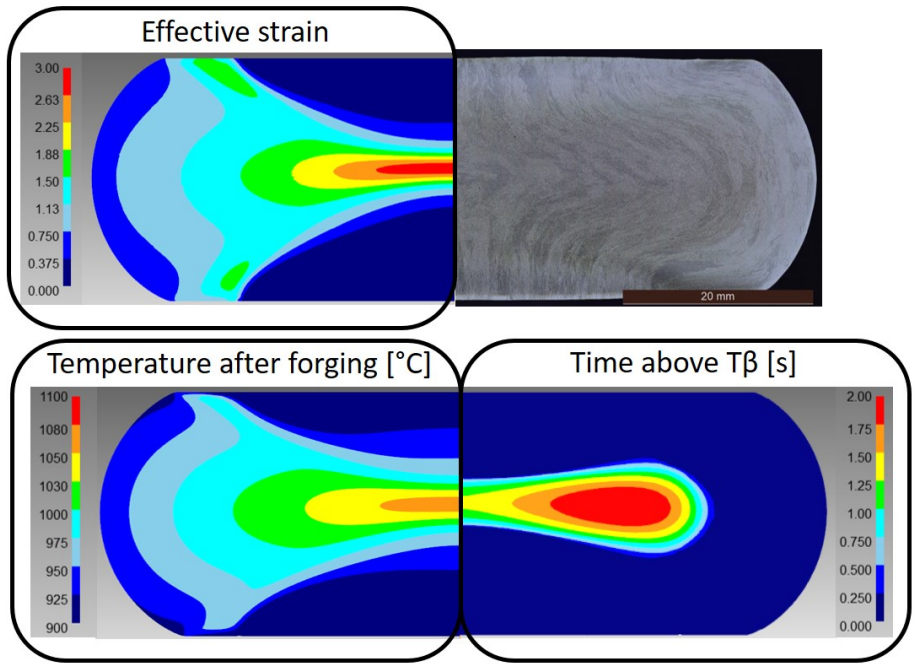

Figure 5 Distribution of strain, temperature after forging and time above $\beta$ transus for $\varnothing 45 \times 67.5 \mathrm{~mm}$ billet forged at $950{ }^{\circ} \mathrm{C}$

There is always a question of the applicability of laboratory results obtained on small test pieces to large-scale industrial forging. The strain and the temperature increase due to adiabatic heating will be approximately the same for all cylinders having the same height-to-diameter aspect ratio and subjected to the same level of reduction during forging. However, as the billet size increases, the efficiency of heat dissipation decreases resulting in lower cooling rates and potentially longer times above the $\beta$ transus. The effect of the billet size on the time above the $\beta$ transus for Ø45, 65 and 85 $\mathrm{mm}$ cylinders having the aspect ratio of 1.5 is shown in Figure 6 based on simulations of forging under identical conditions. As the billet diameter is increased by a factor of about 2 , the time above the $\beta$ transus increases by a factor of about 3 . Therefore, the effect of adiabatic heating on microstructure might be much more significant during forging of large billets compared to the percentage of transformed $\beta$ shown in Figure 4 for $\varnothing 45 \times 67.5 \mathrm{~mm}$ billets. 


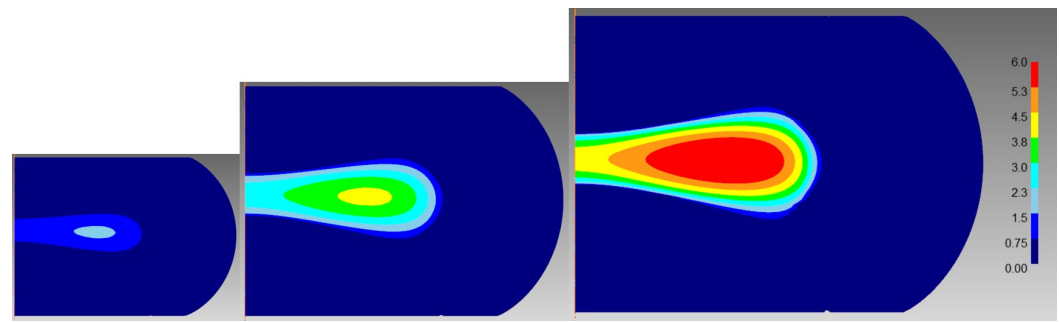

Figure 6 Time above $\beta$ transus for three cylinder sizes $\emptyset 45 \times 67.5, \varnothing 65 \times 97.5$ and $\varnothing 85 \times 127.5 \mathrm{~mm}$ forged at $950{ }^{\circ} \mathrm{C}$

\section{Conclusions}

- Based on experimental measurements of temperature changes during forging at four subtransus temperatures, the temperature went above the $\beta$ transus in the centre of a billet; however, adiabatic heating did not cause significant changes in $\beta$ phase volume fraction during the high strain rate deformation and post-deformation cooling

- The experimentally measured temperature increase due to adiabatic heating is lower compared to model predictions (due to the relatively slow response of the thermocouple and the uncertainty in the thermocouple position); however, there is a good agreement for the time above the $\beta$ transus between experimental measurements and simulation results

- Based on simulation results, the location where temperature stayed above the $\beta$ transus for the longest time does not correspond to the location of the highest strain; the region between the centre and the mid-radius in the mid-height plane experiences temperatures above $\beta$ transus for the longest time

- The time above $\beta$ transus increases by a factor of about 3 as the billet diameter is almost doubled so it is thought that adiabatic heating might have a more significant effect on microstructure during industrial scale forging of large billets

\section{Acknowledgements}

The authors wish to acknowledge financial support for this project from the Advanced Forming Research Centre's Tier 1 members through the Core research programme.

\section{References}

1. J.M Sosa, D.E. Huber, B. Welk and H.L. Fraser, Integrating Materials and Manufacturing Innovation. 3(2014) 18 pages

2. M. Ntovas and P. Blackwell, In: Proceedings of the 20th International ESAFORM Conference on Material Forming, AIP Conf. Proc. 2017 p. 190002

3. M. Boivineau, C. Cagran, D. Doytier, V. Eyraud, M.-H. Nadal, B. Wilthan, and G. Pottlacher, Int. J. Thermophys. 27(2006) 507-529

4. S.-L. Chen, F. Zhang, F.-Y. Xie, S. Daniel, X.-Y. Yan, Y.A. Chang, R. Schmid-Fetzer and W.A. Oates, JOM. 55(2003) 48-51 